\title{
Stan obecny i perspektywy rozwoju dynamicznej regulacji źródeł prądu do spawania GMA
}

\author{
Current status and prospect development \\ of dynamic regulation for GMA welding power sources
}

\section{Streszczenie}

Zaawansowane koncepcje systemów sterowania źródeł spawalniczych umożliwiają użytkownikowi dostosowanie dynamicznych właściwości źródła energii do warunków spawania procesami GMA. Artykuł dotyczy parametrów procesu spawania, które mogą być określone jako zmienna "dynamika łuku" w nowoczesnych źródłach zasilania np. inwertorach nowej generacji MICOR, służą rozszerzeniu przydatności technologicznej metod GMA oraz niwelują niedoskonałość doboru parametrów spawania. Przedstawiono korzyści technologiczne i przykłady zastosowania podczas prac spawalniczych.

Słowa kluczowe: Lorch, inwertory spawalnicze, sterowanie synergiczne

\begin{abstract}
High-quality operating concepts enable the user to adjust dynamic properties of the welding power source for GMA standard welding processes. The article is thematically concerned with parameters what can be summarized under the term "dynamic" for modern inverter power sources and process engineering what effects arise thereby. The technological and practical benefits are considered.
\end{abstract}

Keywords: Lorch, welding inverters, synergic control

\section{Wstęp}

W ostatnich latach obserwowany jest szybki rozwój nowoczesnych urządzeń spawalniczych sterowanych cyfrowo opartych na zasilaczach inwertorowych [1]. Zasilacze spawalnicze wysokiej częstotliwości umożliwiają budowę urządzeń spawalniczych sterowanych programami pracy dedykowanymi do specyficznych warunków spawania, takie dopasowanie owocuje m.in. znaczącym wzrostem wydajno-

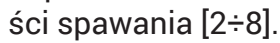

Właściwości spawalniczych źródeł energii mogą być m.in. opisane charakterystyką statyczną zewnętrzną, czyli w odniesieniu do powolnych zmian obciążenia rezystancyjnego. Charakterystyki statyczne reprezentują relację pomiędzy natężeniem prądu płynącego w obwodzie wtórnym, a napięciem mierzonym na zaciskach wyjściowych zasilacza podczas obciążania rezystancyjnego urządzenia spawalniczego. Urządzenia o stosunkowo prostej konstrukcji, czyli transformatorowe źródła napięcia z mostkiem prostowniczym charakteryzują się skokową nastawą napięcia, co znajduje odwzorowanie na rysunku 1. Szeregiem różnych charakterystyk statycznych, właściwych dla określonych odczepów transformatora (S), którym odpowiada określone napięcie stanu jałowego $U_{0}$, prąd zwarcia $I_{K}$ oraz nachylenie charakterystyki (du/di) w punkcie pracy.

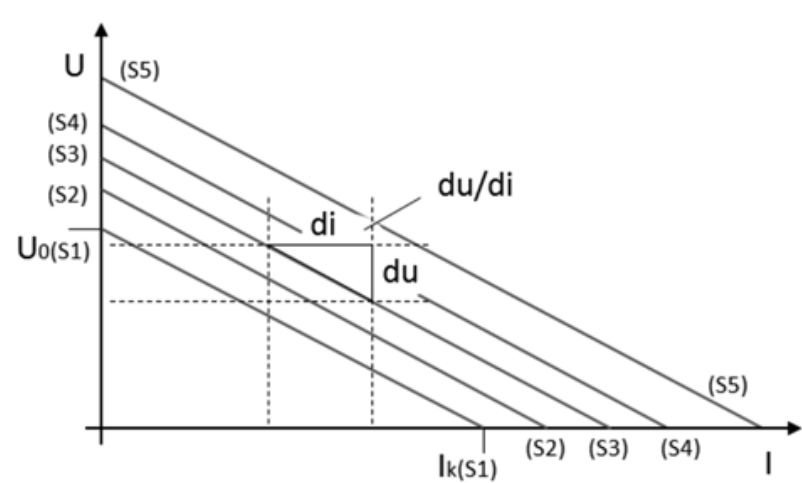

Rys. 1. Schemat statycznych charakterystyk U(I) z użyciem klasycznego urządzenia transformatorowego przy różnych skokowo regulowanych nastawach parametrów. S1 ..S5 = poziomy nastaw

Fig. 1. Schematic representation of the static C-V characteristics of a traditional step switched welding power source. S1..S5 = levels

Na rysunku 2 zobrazowano przecięcie charakterystyki łuku (znormalizowanej charakterystyki napięcia roboczego) (LK), która jest determinowana przez szereg różnego rodzaju oddziaływań fizycznych w obszarze łuku z określoną charakterystyką statyczną źródła, wynikającą z wybranego odczepu (poziomu mocy). Punk przecięcia charakterystyk jest punktem pracy, determinującym warunki spawania.

Dr inż. Marek Węglowski - Akademia Spawania, dr Birger Jaeschke - LORCH Schweißtechnik GmbH, dr hab. inż. Tomasz Chmielewski, prof. PW - Politechnika Warszawska. 
Dokładne położenie punktu pracy na charakterystyce statycznej zależy od procesu spawania łukowego, oraz od wartości posuwu drutu elektrodowego. W każdym procesie spawania łukowego mamy do czynienia ze zmianą długości łuku podczas pracy, aż do zwarcia, co jest najbardziej ekstremalnym rezultatem zmiany długości łuku, bliskim zera, rzeczywisty punkt pracy mniej lub bardziej regularnie przemieszcza się w obrębie obszaru blisko punktu pracy.

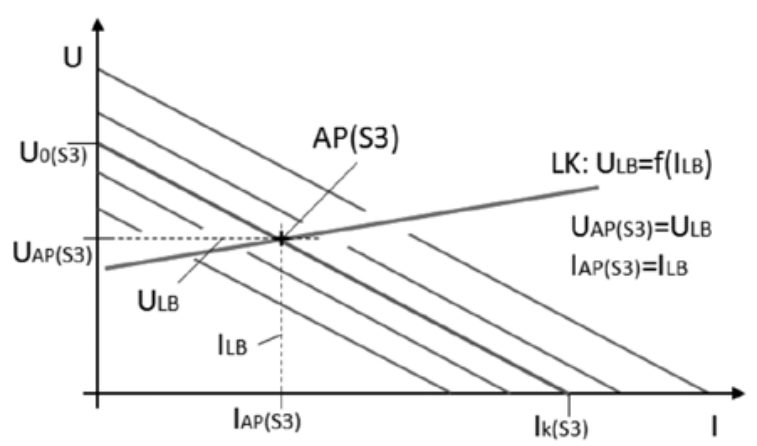

Rys. 2. Schematyczne przedstawienie warunków spawania (AP) jako punkt przecięcia charakterystyki statycznej źródła napięcia (w tym przypadku S3) ze znormalizowaną charakterystyką napięcia roboczego (łuku) (LK)

Fig. 2. Schematic representation of the formation of a common operating point (AP) as the intersection of the set static characteristic of the welding power source (in this example S3) with the static load characteristic curve (LK) of the arc

W urządzeniach do spawania w grupie metod GMA celowo wprowadza się możliwość zmiany indukcyjności obwodu spawania (tzw. dławik), która wpływa na przechodzenie kropli w łuku natryskowo lub zwarciowo, a zarazem obniżenie statycznej charakterystyki zewnętrznej spawania źródła zasilania, pokazanej na rysunku 3, poprzez krótkie ładowanie dodatkowej energii, która ma być uwalniana do obwodu spawania po oderwaniu kropli.

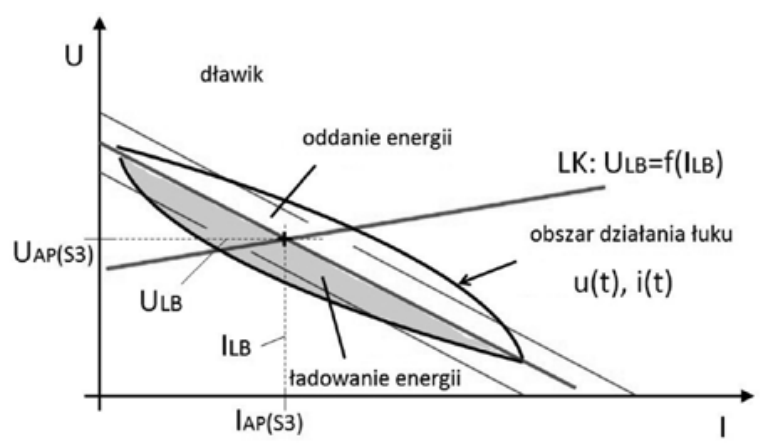

Rys. 3. Schemat wpływu zmiany indukcyjności (dławika) w punkcie pracy źródła napięcia oraz charakterystykami statycznymi zewnętrznymi

Fig. 3. Schematic representation of the effect of a choke in the expansion of a static operating point from welding power source and static load characteristic to a dynamic operation area of a short-circuit-free arc welding process

Zwiększenie lub zmniejszenie przepływu prądu jest tłumione przez dławik o odpowiedniej indukcyjności, dodatkowa energia pochłaniana i uwalniana jest z opóźnieniem, w zależności od warunków spawania, wynikające z tego przemieszczenia punktu pracy nazywane są dynamicznym ruchem punktu pracy. Szczególnie widoczne jest oddziaływanie na statyczne i dynamiczne właściwości spawania źródła zasilania, w przypadku przechodzenia kropli w sposób zwarciowy, pokazane na rysunku 4 i 5 . Dla uzyskania stabilnego procesu spawania, opisane parametry muszą być dobrze skoordynowane: wzrost natężenia prądu podczas zwarcia i jego obniżenie w fazie palenia łuku bez zwarcia, średnia wartości napięcia łuku i natężenia prądu spawania podczas zwarcia i fazy bez zwarcia łuku, a także wartość posuwu drutu. Zakres wpływania na właściwości tradycyjnego źródła napięcia przez dostosowywanie charakterystyki statycznej i dynamicznej za pomocą dławika są niewielkie, z czego wynikają ograniczenia zdolności adaptacyjnych konwencjonalnych źródeł energii spawania. Cyfrowo sterowane źródła napięcia mogą zmieniać opisane relacje fizyczne pomiędzy charakterystyką statyczną i dławikiem. W nowoczesnych cyfrowych źródła zasilania, funkcjonuje $w$ zasadzie nieograniczona liczba wariantów zmian różnych parametrów w procesie spawania, co pokazano na rysunku 6 . Oznacza to, że można w szerokim stopniu wpływać na właściwości klasycznego źródła energii poprawiając jego działanie w znacznie szerszym zakresie niż stosując klasyczny dławik.

$\mathrm{Na}$ obecnym etapie rozwoju cyfrowych systemów sterowania urządzeniami spawalniczymi, duże wyzwanie dla projektantów urządzeń stanowi problem połączenia możliwości regulacyjnych nowoczesnych urządzeń z łatwością ich obsługi przez przeciętnego użytkownika.

Rysunek 6 przedstawia przebieg czasowo-prądowy spawania dla procesów GMA podczas przejścia metalu do jeziorka w sposób zwarciowy. Strzałki na rysunku wskazują kilka stopni swobody w regulacji natężenia prądu spawania. Każdy z tych stopni swobody przypisany jest do określonego parametru, który wpływa na jego wartość na określonym

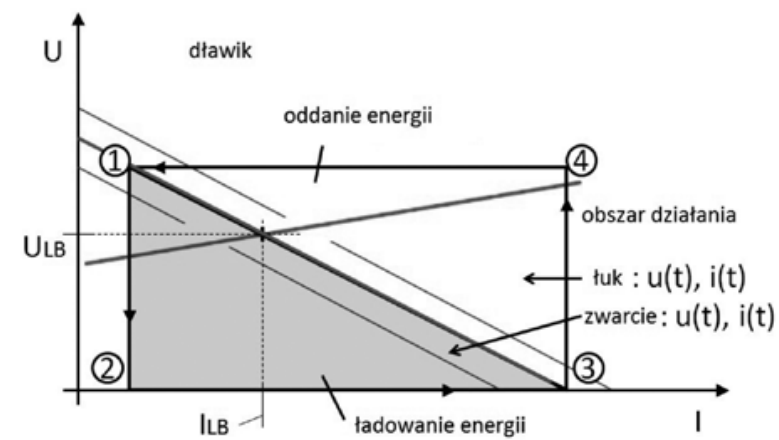

Rys. 4. Schematyczne przedstawienie wpływu indukcyjności (dławika) w punkcie pracy spawania źródła zasilania i statycznej charakterystyki zewnętrznej dla dynamicznego obszaru roboczego w łuku zwarciowym; strzałki wskazują kierunek ruchu punktu pracy Fig. 4. Schematic representation of the effect of a choke in the expansion of a static operating point from welding power source and static load characteristic to a dynamic operation area of an idealized shortcircuited arc process; the arrows indicate the direction of the operating point movements

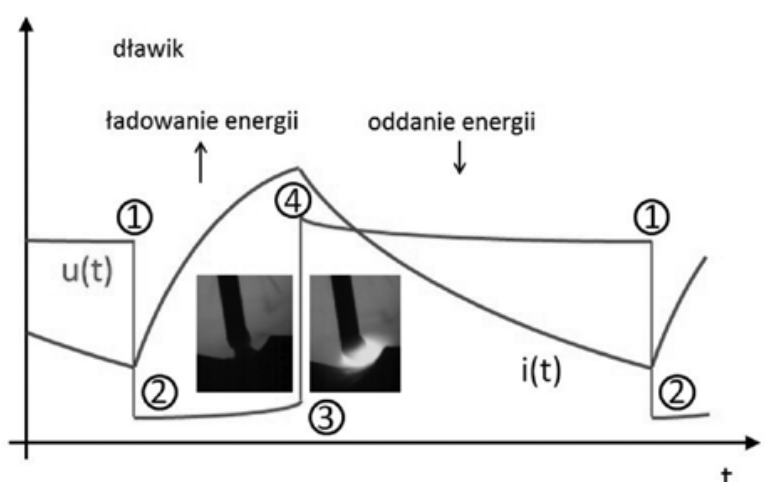

Rys. 5. Wpływ indukcyjności (dławika) w odniesieniu do charakterystyki dynamicznej spawania przedstawionej w czasie, napięcia spawania U (t) oraz prądu spawania I (t) podczas zwarciowego przechodzenia metalu do jeziorka spawalniczego; w odniesieniu do punktu pracy pokazanym na rys. 4

Fig. 5. Effect of the choke in the temporal waveform of welding voltage $u(t)$ and welding current $i(t)$ of a non-idealized process with short-circuited material transfer; with respect to the operating point identification in Fig. 4 
etapie cyklu. Wszystkie parametry muszą być odpowiednio dopasowane, tak, aby powodowały korzystne zmiany właściwości technologicznych procesu spawania. Dobór parametrów zwykle jest dokonywany przez producenta źródła spawania na drodze wielu długotrwałych, kosztownych i skomplikowanych prac badawczo-rozwojowych. Do ustalenia optymalnych wartości poszczególnych parametrów można dojść jedynie na drodze prób spawalniczych, budując bibliotekę parametrów i programów spawania (krzywych synergicznych) z której układ sterowania czerpie informacje potrzebne do ich automatycznego ustalania.

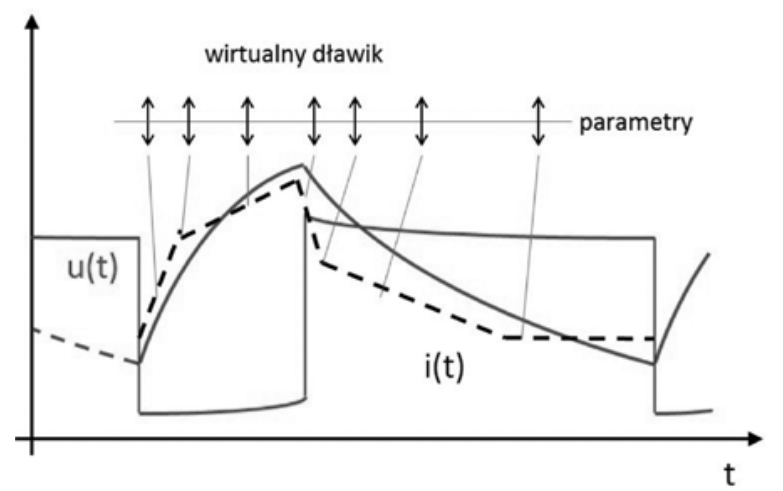

Rys. 6. Przykład korekcji warunków spawania w cyfrowo sterowanym urządzeniu spawalniczym

Fig. 6. Example of parameters for the virtual choke of a digitally controlled welding power source

Zmiana jednego parametru spawania, powinna wiązać się z automatyczną regulacją i zmianą wszystkich pozostałych parametrów, przy czym koordynacja parametrów jest utrzymywana w taki sposób, aby proces spawania przebiegał bez utrudnień. W przypadku impulsowych źródeł spawania, kontrola synergiczna jest od wielu lat stosowana, również w standardowych procesach spawania GMA. Krzywe synergiczne są scharakteryzowane do wyboru danej kombinacji: materiał podstawowy/drut elektrodowy/gaz osłonowy. Z poziomu operatora posuw drutu jest zwykle bezpośrednim wiodącym parametrem wybieranym przez użytkownika, służącym do wyboru właściwych krzywych synergicznych. W niektórych przypadkach średnie natężenie prądu spawania jest wiodącym parametrem do którego system synergiczny dostosowuje inne parametry. Procesy spawania GMA w rzeczywistości reguluje się napięciem łuku [9] natomiast natężenie prądu spawania uzależnione jest od prędkości posuwu drutu, a nie na odwrót. W rzeczywistości, układ sterowania interpretuje pośrednie parametry natężenia prądu jako wartości prognozowane i odpowiednio dobiera krzywe synergiczne. Parametry te są mierzone i wyświetlane na panelu operatora w czasie rzeczywistym podczas spawania, jednak nastawy nie są ściśle dostosowywane do wartości wybieranych przez użytkownika. Średnie napięcie łuku może zostać zmienione w każdym momencie lub może być skorygowane bezpośrednio podczas procesu spawania w celu uzyskania wysokiej jakości spoiny lub w celu dostosowania do różnych innych warunków spawania. Jak we wszystkich innych sposobach sterowania wyborem parametrów, system synergiczny nie jest odporny na wybór błędnych danych wejściowych przez operatora. Każde urządzenie sterowane synergicznie posiada możliwość wyboru parametrów spawania w „trybie ręcznym”, kiedy wartość każdego z parametrów dobierana jest indywidualnie.

\section{Dynamiczna korekta}

Jest wiele powodów, aby wpływać na zmiany charakterystyk dynamicznych podczas procesu spawania, nawet jeśli początkowe ustawienia (np. wygenerowane przez synergiczny system sterowania) umożliwiają stabilne spawanie. Głównym powodem jest subiektywna ocena przebiegu procesu łukowego spawania przez spawacza, oraz możliwość dopasowania warunków do swoich własnych potrzeb i oczekiwań najczęściej trudnych do sparametryzowania. Urządzenia wyposażone w takie dodatkowe parametry będą mogły spełniać wszystkie indywidualne oczekiwania i wymagania spawacza np. „twardy”, „średni” lub „miękki” łuk spawalniczy.

Urządzenia marki LORCH MicorMIG umożliwiają określenie dynamiki łuku jako indywidualnie dobieranego parametru, wyświetlanego na panelu głównym w urządzeniach poprzez ustawienie „Dynamicznego łuku” pokazanego na rysunku 7.

\section{.011}

Rys. 7. "Dynamika łuku” nastawa parametrów Lorch MicorMig z panelu sterowania BasicPlus

Fig. 7. The "dynamics" setting parameter of the LORCH MicorMig with BasicPlus control panel
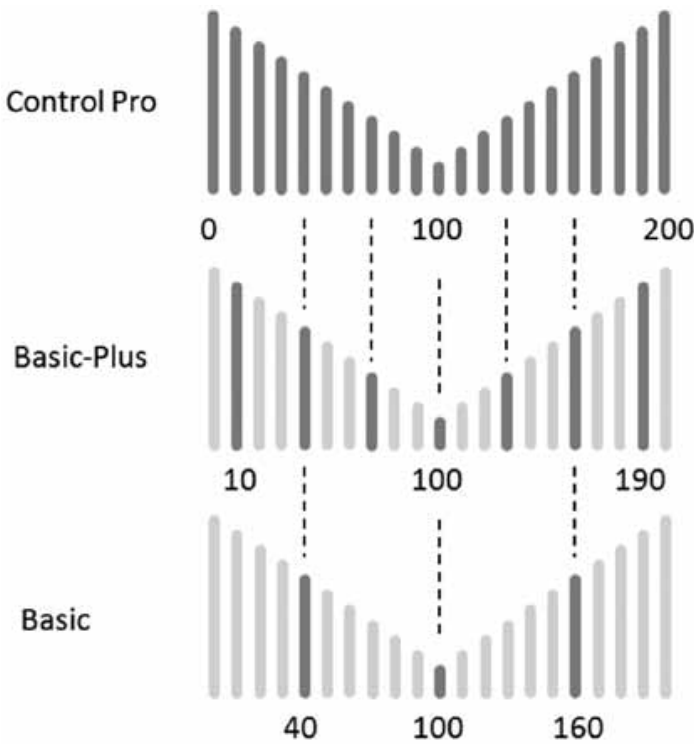

Rys. 8. Różne rodzaje panelu sterowania oferują stopniowe dostosowanie dynamiki łuku spawania

Fig. 8. Different control panel types offer staggered adjustment of process dynamics

Na rysunku 8 pokazano różne warianty panelu sterowania oraz opcji ustawień.

Głównym zadaniem parametru „dynamiki łuku” jest regulacja łuku tak aby spełnić oczekiwania spawacza z możliwością jednoczesnego synergicznego doboru pozostałych parametrów spawania. Korekta "dynamiki łuku”, nie powinna negatywnie wpływać na wartość zasadniczych parametrów spawania. Zespół badaczy, który został powołany przez firmę Lorch dał podstawę do znalezienia odpowiednich rozwiązań technicznych $\mathrm{w}$ kontekście praktycznych badań. Potrzebne było stopniowe i odpowiednie dostosowanie różnych dodatkowych parametrów, które określają przebieg procesu spawania jak pokazano na rysunku 6, które pochodzą z nastaw krzywych synergicznych. Dynamiczna regulacji łuku jest możliwa zarówno podczas używania sterowania synergicznego, jak również w trybie ustawienia ręcznego z ukrytą synergią. Aby proces spawania odbywał się stabilnie wymagane, jest to aby "dynamika łuku" była osadzona w charakterystyce synergii.

Opcje dodatkowe stopniowej regulacji są pokazane na rysunku 9, na przykładzie zwarciowego przechodzenia 
kropli w łuku spawalniczym. Zmiana subiektywnej oceny spawacza dotyczącej łuku i określenie jej jako łuk "twardy" czy „miękki”, realizowana jest poprzez zmianę działania łuku w stałych warunkach czyli przy stałym posuwie drutu elektrodowego jednak przy zmieniających się: napięciu łuku i średnim natężeniu prądu spawania. Podczas zmiany ustawień „dynamiki łuku”, z jednej strony należy uzyskać pożądany stabilny łuk spawalniczy z małą liczbą rozprysków przy niezmienionej wartości posuwu drutu, a z drugiej strony, automatyczną kontrolę zmiany wartości napięcia łuku.

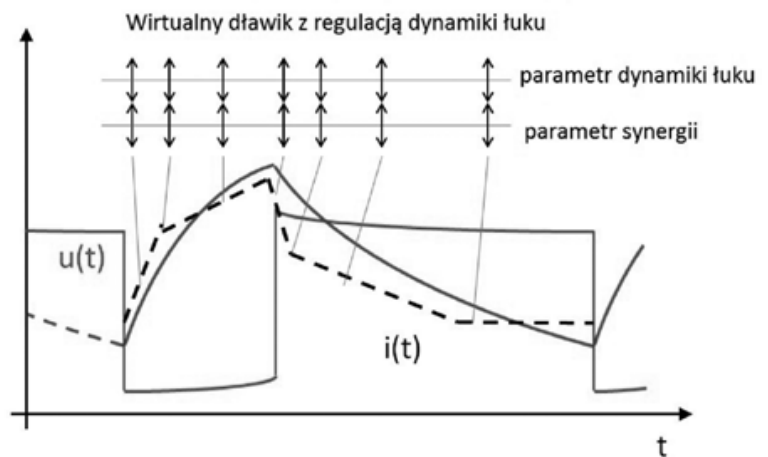

Rys. 9. Przykład ingerencji „wirtualnego dławika” z możliwością regulacji dynamiki łuku w cyfrowo sterowanym urządzeniu spawalniczym Fig. 9. Example of parameters for the "virtual choke" of a digitally controlled welding power source with additional options for adjusting the dynamics

\section{Efekt techniczny}

W nowoczesnych urządzeniach spawalniczych sterowanych cyfrowo - dynamiczna regulacja przebiegu charakterystyki czasowej prądu i napięcia zapewnia stabilny zapłon łuku. Dzięki zaprogramowaniu dynamicznego wzrostu napięcia, a tym samym mocy łuku uzyskuje się szybkie topienie końca drutu elektrodowego w fazie początkowej, co zapobiega rozpryskowi początkowemu (rys. 10).

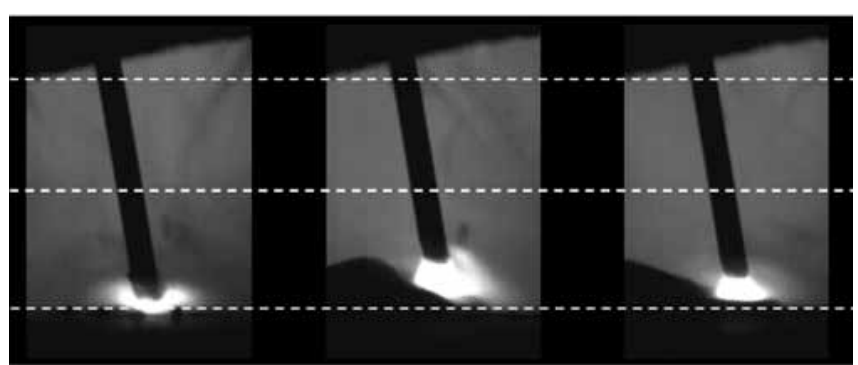

Rys. 10. Rozpoczęcie procesu spawania z "gorącym startem"; 1) początkowy zapłon łuku po przez wzrost dynamiki; 2) formowanie się jeziorka spawalniczego wraz ze wzrostem napięcia łuku i dostosowaniem dynamiki łuku; 3)stabilizowanie procesu spawania po rozpoczęciu spawania

Fig. 10. Start of a welding process with "hot start"; 1) initial ignition of the arc through highly dynamic upslope; 2) forced formation of the melt pool with increased arc voltage and adapted dynamic; 3) stabilized arc welding process for the actual weld after start-up

Podczas spawania, wybrane odpowiednie nastawy przez użytkownika z krzywych synergicznych pod wpływem zmian dynamiki łuku mogą być korygowane podczas spawania, zwłaszcza, gdy przejście materiału jest w sposób zwarciowy. Na rysunku 11 pokazano skutki zmian "dynamiki łuku”. Korekta "dynamiki łuku” w lewo, czyli obniżenie wartości, powoduje bardziej „miękki” łuk, pozostając w korelacji wzrostu napięcia i energii cieplnej łuku. Łuk oraz jeziorko staje się większe, szersze, łuk jaśniejszy i bardziej elastyczny. Przykładowo ten rodzaj łuku jest odpowiedni do spawania grani spoin z ukosowaniem na V, lub wklęsłych spoin pachwinowych z płaskim licem, a także materiałów o stosunkowo wysokim współczynniku przewodzenia ciepła, daje szczególnie mało odprysków, co może znaleźć zastosowanie w wielu aplikacjach. Regulacja "dynamiki łuku” w prawą stronę, czyli zwiększenie wartości, prowadzi do bardziej „twardego" łuku, w połączeniu z wyraźnie mniejszym napięciem i niższą energią cieplną. Łuk jest bardziej skoncentrowany, wąski, "sztywny". Ten rodzaj łuku jest odpowiedni do spawania spoin narożnych lub cienkich elementach oraz materiałów o niskiej przewodności cieplnej.
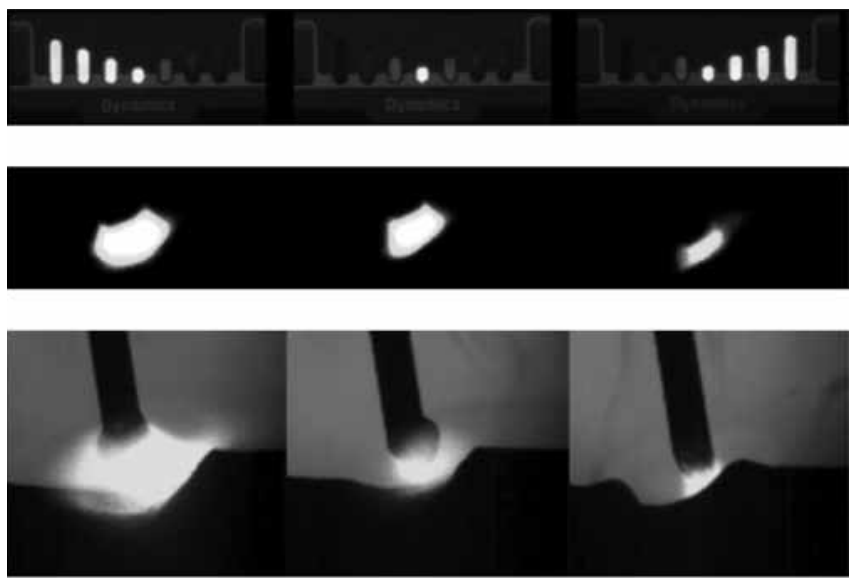

Dynamics
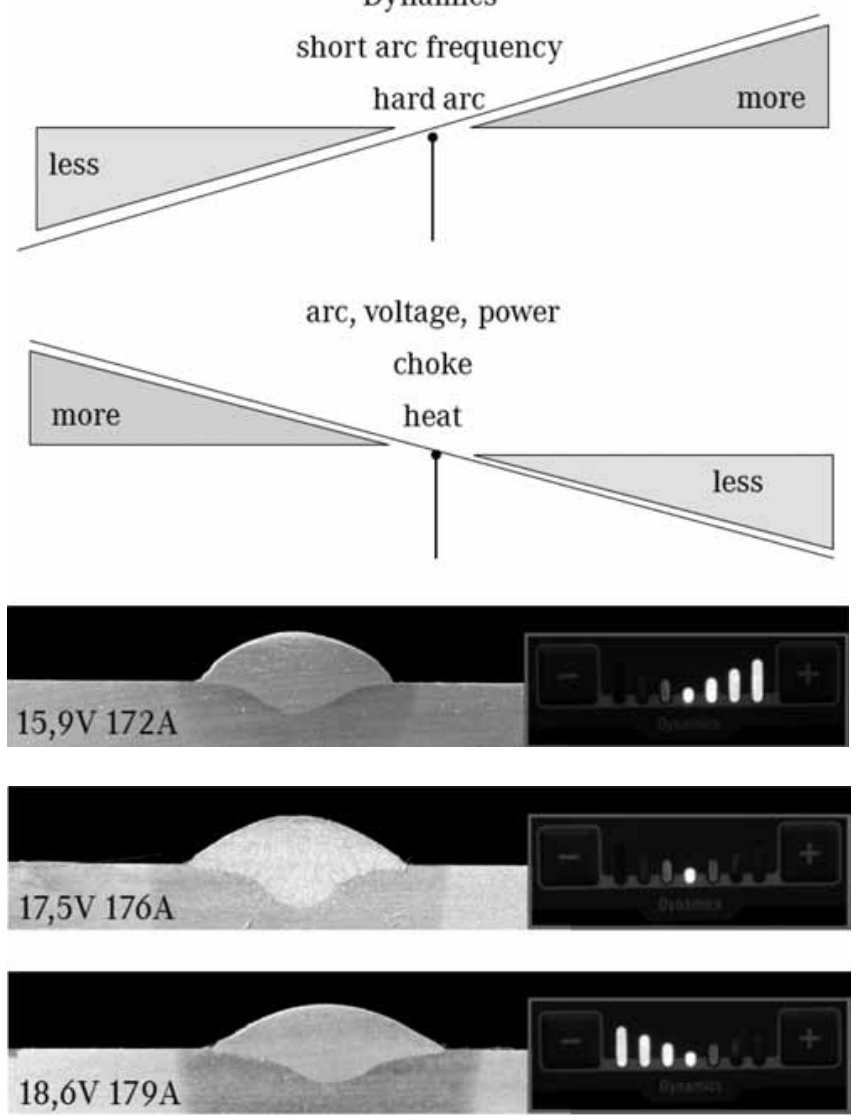

Rys. 11. Skutki nastawy "dynamiki łuku” przy różnych nastawach parametrów, warunki spawania: drut elektrodowy $\varphi 1.2 \mathrm{~mm}$ gat. G3Si1, stal S355 gr. $4 \mathrm{~mm}$, posuw drutu elektrodowego $4,5 \mathrm{~m} / \mathrm{min}$, prędkość spawania $=0,20 \mathrm{~m} / \mathrm{min}$

Fig. 11. Effects of the "dynamics" adjusting parameter, welding conditions: electrode wire $41.2 \mathrm{~mm}$ G3Si1, welding native material steel $\mathrm{S} 3554 \mathrm{~mm}, \mathrm{Vd} 4.5 \mathrm{~m} / \mathrm{min}$, Vs $0,20 \mathrm{~m} / \mathrm{min}$ 


\section{Podsumowanie i wnioski}

Nowoczesne źródła zasilania z wykorzystaniem falownika w stosunku do standardowego źródła spawania GMA charakteryzują się nie tylko bezstopniową regulację napięcia w stosunku do skokowej nastawy transformatora, ale również oferują znacznie więcej korzyści użytkownikowi z ich zaawansowanymi funkcjami i możliwościami aplikacyjnymi. Podstawą do tego jest możliwość regulacji dynamiki łuku przy zachowaniu stabilnego łuku oraz małej ilości odprysków. Dynamiczna regulacja łuku w źródłach zasilania spawania GMA, zapewnia użytkownikowi prosty i praktyczny sposób na regulację właściwości źródła napięcia do jego określonych potrzeb. Praktyczne zastosowanie regulacji dynamiki łuku jest możliwe dzięki nowoczesnym sterowanym cyfrowo źródłom napięcia, które są dostępne na rynku w postaci serii Micor-MIG firmy Lorch.

\section{Literatura}

[1] T. Chmielewski, M. Węglowski, „Analiza rynku spawalniczego w Polsce pod względem sprzedaży urządzeń oraz materiałów spawalniczych" Przegląd Spawalnictwa, Vol. 82, No 10, s.28-31, 2010.

[2] T. Chmielewski, M. Węglowski, K. Kudła, „Spawanie w pozycji PF metodą MMA z wykorzystaniem nowej funkcji UP w zasilaczach inwertorowych zbudowanych w technice MICOR", Przegląd Spawalnictwa, Vol. 86, No 9, s.45-49, 2014.

[3] T. Chmielewski, M. Węglowski, K. Kudła, "Nowe funkcje zasilaczy inwertorowych zbudowanych techniką MICOR do metody MMA", Przegląd Spawalnictwa, Vol. 85, No 10, s.59-64, 2013.

[4] M. Węglowski, T. Chmielewski, K. Kudła, "Ocena wydajności spawania niskoenergetycznego procesu SpeedRoot w pozycji PG", Przegląd Spawalnictwa, Vol. 83, No 12, s.26-30, 2011.

[5] M. Węglowski, T. Chmielewski, K. Kudła, „Porównanie wybranych właściwości nowoczesnych spawalniczych inwertorowych źródeł energii przeznaczonych do spawania metodą MAG", Przegląd Spawalnictwa, Vol. 81, No 10, s.81-83, 2009
[6] M. Weglowski, T. Chmielewski, K. Kudła, „Productivity assessment of the low-energy SpeedRoot welding process in PG position" WeIding International, Vol. 30 (3), s.192-195, 2016, DOI:10.1080/09507 116.2014.937621

[7] M. Węglowski, T. Chmielewski, K. Kudła, „Ocena wydajności spawania w wysoko wydajnym procesie SpeedUp oraz MAG Standard w pozycji przymusowej", Biuletyn Instytutu Spawalnictwa, Vol.54 (5), s.199201, 2010.

[8] T. Chmielewski, K. Kudła, M. Weglowski, „Analysis of the Effect of Arc Welding Characteristics in Modern MAG Welding Variants on Welding Properties and Weld Geometry", Biuletyn Instytutu Spawalnictwa, Vol.58 (5), s.196-203, 2014.

[9] T. Chmielewski, „Projektowanie procesów technologicznych - Spawalnictwo”, Oficyna Wydawnicza Politechniki Warszawskiej, 2013. 